\title{
Non-nosocomial healthcare-associated infective endocarditis in Taiwan: an underrecognized disease with poor outcome
}

\author{
Kuan-Sheng Wu', Susan Shin-Jung Lee ${ }^{2,1}$, Hung-Chin Tsai ${ }^{1,2}$, Shue-Ren Wann ${ }^{1}$, Jui-Kuang Chen ${ }^{1}$, Cheng-Len Sy ${ }^{1}$, \\ Yung-Hsin Wang ${ }^{1}$, Yu-Ting Tseng ${ }^{1}$ and Yao-Shen Chen ${ }^{1,2,3^{*}}$
}

\begin{abstract}
Background: Non-nosocomial healthcare-associated infective endocarditis (NNHCA-IE) is a new category of IE of increasing importance. This study described the clinical and microbiological characteristics and outcome of NNHCA-IE in Taiwan.

Methods: A retrospective study was conducted of all patients with IE admitted to the Kaohsiung Veterans General Hospital in Kaohsiung, Taiwan over a five-year period from July 2004 to July 2009. The clinical and microbiological features of NNHCA-IE were compared to those of community-acquired and nosocomial IE. Predictors for in-hospital death were determined.

Results: Two-hundred episodes of confirmed IE occurred during the study period. These included 148 (74\%) community-acquired, 30 (15\%) non-nosocomial healthcare-associated, and 22 (11\%) nosocomial healthcare-associated IE. Staphylococcus aureus was the most frequent pathogen. Patients with NNHCA-IE compared to community-acquired IE, were older (median age, 67 vs. 44, years, $p<0.001$ ), had more MRSA (43.3\% vs. 9.5\%, $p<0.001$ ), more comorbidity conditions (median Charlson comorbidity index [interquartile range], 4[2-6] vs. 0[0-1], $p<0.001$ ), a higher in-hospital mortality $(50.0 \%$ vs. $17.6 \%, p<0.001)$ and were less frequently recognized by clinicians on admission $(16.7 \%$ vs. $47.7 \%$, $p=0.002$ ). The overall in-hospital mortality rate for all patients with IE was $25 \%$. Shock was the strongest risk factor for in-hospital death (odds ratio 7.8, 95\% confidence interval 2.4-25.2, $p<0.001$ ).
\end{abstract}

Conclusions: NNHCA-IE is underrecognized and carries a high mortality rate. Early recognition is crucial to provide optimal management and improve outcome.

\section{Background}

Infective endocarditis (IE) is a serious disease with a high mortality rate, of up to $16-25 \%$ [1-6]. Major changes have occurred in the epidemiology of IE in association with advances in medical and surgical care. Rheumatic heart disease has been replaced as the major risk factor for IE by degenerative valve diseases, hemodialysis, prosthetic valve replacement, and intravenous drug use (IVDU) [2,7-10]. Staphylococci, instead of Streptococci, have become the most common pathogen in IE patients in recent series $[7,8,11]$.

\footnotetext{
* Correspondence: yschen@vghks.gov.tw

'Divison of Infectious Diseases, Department of Medicine, Kaohsiung Veterans General Hospital, 386 Ta-Chung 1st Road, Kaohsiung 813, Taiwan

Full list of author information is available at the end of the article
}

Nosocomial IE is associated with the highest mortality rate among all forms of IE [10,12]. Nosocomial acquisition is considered when IE occurs within the hospital or in recently hospitalized patients $[12,13]$. Within the past two decades more invasive procedures and life-support measures, previously limited to hospitals are now performed in chronic care facilities or at home. A new category of IE, non-nosocomial healthcare-associated IE (NNHCA-IE), was recently introduced to encompass these changes in medical practice. This new entity is defined as an episode of IE in out-patients who had extensive exposure to medical care [14-17].

NNHCA-IE has been reported to contribute to $9.3 \%$ of all IE episodes [15]. The highest percentage was noted in North America. A large prospective, multicenter,

\section{C) Biomed Central}


international study, the International Collaboration of Endocarditis-Prospective Cohort Study (ICE-PCS) [15], mainly focused on the Americas and Europe. Only a few study sites were located in Western, Southern and Southeastern Asia. A subgroup analysis for these regions has not as yet been reported [15]. Patients with NNHCA-IE were found to have clinical features and outcomes similar to those with nosocomial IE [14]. Because these infections occur outside the hospital, clinicians appear to be unaware of the need to identify these cases and provide optimal antimicrobial therapy.

To our knowledge, NNHCA-IE has not been reported previously in Eastern Asia (including China, Hong Kong, Taiwan, Japan, Mongolia, North Korea and South Korea). Among the studies of IE conducted in this region $[4,5,18-23]$, only two included nosocomial IE. Nosocomial acquisition was found to be an independent factor for poor prognosis $[4,18]$. However, the definitions of nosocomial IE were not clearly defined in these studies. It is also unclear whether NNHCA-IE was adequately distinguished from community-acquired or nosocomial-acquired IE. To better characterize the prevalence, causative microorganisms, clinical features and outcome of non-nosocomial healthcare-associated IE in Eastern Asia, we conducted a five-year retrospective study of all cases of IE in a large medical center in southern Taiwan.

\section{Methods}

\section{Patients}

Medical records of patients more than 18 years old with IE who were admitted to the Kaohsiung Veterans General Hospital (KVGH) from July 2004 to July 2009, were reviewed retrospectively. KVGH is a 1,200-bed teaching hospital. It provides both primary and tertiary medical services in Kaohsiung, a city with 1.52 million residents located in southern Taiwan. Medical charts of patients who met the International Classification of Diseases, Ninth Revision (ICD-9) diagnostic codes for endocarditis (ICD-9 codes 421.0, 421.1, and 421.9) were reviewed by infectious disease specialists. Diagnosis of IE were confirmed based on the modified Duke criteria [24]. Only those with definite IE were included to the study. Patients with a relapse of IE, defined as isolation of the same pathogen within a six-month period [17], were excluded. A standardized case report form was designed to collect the clinical characteristics of the patients, including age, sex, clinical manifestations, predisposing heart conditions, underlying diseases, Charlson comorbidity index [25], risk behaviors, causative microorganisms and outcome. The study was approved by the KVGH Institutional Review Board and informed consent was waived because of the retrospective nature of the study, and lack of direct patient contact or intervention.

\section{Definitions}

An IE episode was defined as non-nosocomial healthcareassociated when it occurred within 48 hours of admission in a patient fulfilling at least one of the following criteria: (1) had received intravenous therapy, wound care, specialized nursing care, hemodialysis or intravenous chemotherapy within 30 days prior to the onset of IE, (2) was hospitalized in an acute care hospital for 2 or more days within 90 days before the onset of IE, or (3) resided in a nursing home or long-term care facility before admission $[14,16,17,26]$. An IE episode was defined as nosocomial healthcare-associated if positive blood cultures were obtained from a patient hospitalized for more than 48 hours without relevant symptoms and signs on admission $[14,16,17,26,27]$. The infection was considered to be community-acquired when the symptoms and signs of IE occurred within 48 hours of admission in a patient not fulfilling the criteria for non-nosocomial healthcareassociated infection. IVDU-associated IE was defined as patients actively using illicit intravenous drugs at the time of infection. A predisposing heart condition was defined as a history of prosthetic cardiac valve replacement, previous bacterial endocarditis, congenital cardiac malformation, rheumatic and other acquired valvular dysfunction, hypertrophic cardiomyopathy or mitral valve prolapse with valvular regurgitation $[28,29]$. When a patient was suspected or diagnosed to have IE within the first 24 hours of medical access by clinicians, he was considered to be recognized on admission. Appropriate antibiotics were defined as having in vitro activities against the causative pathogens [30].

Presenting symptoms were divided into 5 symptomatic categories according to site: (1) constitutional including fever, fatigue and weight loss; (2) cardiopulmonary including dyspnea, orthopnea and chest pain; (3) neurological including change in consciousness, syncope and focal neurological deficits; (4) gastrointestinal including nausea, vomiting, abdominal pain and diarrhea; (5) musculoskeletal including focal arthralgia or myalgia, skin rash, subcutaneous abscess and cellulitis.

\section{Statistical analysis}

In univariate analysis, categorical variables were compared using $\chi^{2}$ test or Fisher's exact test as appropriate. Continuous variables were analyzed by Mann-Whitney $\mathrm{U}$ test. The result was considered to be significant if a two-tailed $p$ value was less than 0.05 . Variables with a $p$ value of less than 0.05 in univariate analysis were included in multivariate logistic regression analysis by forward stepwise method using $p$ values less than 0.05 as inclusion criterion and 0.1 as removal criterion. All data were analyzed by SPSS 17.0 for Windows (SPSS Inc. Chicago, USA). 


\section{Results}

During the five-year study period, 481 admissions with compatible ICD-9 codes for IE were reviewed. We identified 205 episodes of definite IE and 32 of possible IE. We excluded 5 patients with definite IE because they were considered to have had a relapse and all cases of possible IE. The final study population consisted of 192 patients with 200 episodes of definite IE, of which 168 (84\%) were diagnosed by clinical and $32(16 \%)$ by pathological criteria. There were 148 (74\%) episodes of community-acquired and $52(26 \%)$ healthcare-associated IE. Thirty $(57.7 \%)$ of the 52 healthcare-associated IE were considered to be non-nosocomial. They comprised $15 \%$ of all IE episodes. There were 59 (29.5\%) IVDU-associated IE episodes. All of these were community-acquired. The ten patients with IE and human immunodeficiency virus (HIV) infection were all IVDU-associated. Paravalvular abscess was noted in only one patient, whose IE was community-acquired. Overall, patients who were recognized as having NNHCAIE more frequently received appropriate antibiotics within the first 24 hours of presentation than those who were not (77.6\% vs. $37.6 \%, p<0.001)$.

Of the 30 IE patients who met non-nosocomial healthcare-associated infection criteria, 14 were receiving regular hemodialysis prior to the onset of IE, 19 were recently hospitalized in acute care hospitals for 2 or more days (median duration from the time being discharged to the time IE symptoms began were 33 days, with an interquartile rage of 15-55 days), 4 were nursing home residents and 1 had received intravenous chemotherapy 7 days before the onset of IE.

\section{NNHCA-IE versus community-acquired IE}

The thirty patients with NNHCA-IE were older (median age, 67 vs. 44 , years, $p<0.001$ ), more often female (43.3\% vs. $18.9 \%, p=0.006)$, and had more frequently co-morbidities (median Charlson comorbidity index [interquartile range], 4[2-6] vs. $0[0-1], p<0.001$ ) (Table 1). Up to $60 \%$ of NNHCA-IE patients had Charlson comorbidity indexes of 4 or more. NNHCAIE was more often caused by Staphylococci $(76.7 \%$ vs. $50.7 \%, p=0.015)$, methicillin-resistant Staphylococcus aureus (MRSA) $(43.3 \%$ vs. 9.5\%, $p<0.001)$, and less commonly by Streptococci ( $13.3 \%$ vs. $34.5 \%, p=0.029)$. Patients with NNHCA-IE had a significantly higher inhospital mortality rate $(50.0 \%$ vs. $17.6 \%, p<0.001)$.

\section{NNHCA-IE versus nosocomial IE}

The twenty two patients with nosocomial IE were even older (median age, 78 vs. 67 , years, $p<0.011$ ). There was no significant difference in gender (female, $43.3 \%$ vs. $31.8 \%, p=0.40$ ), Charlson comorbidity index (median [interquartile range], $4[2-6]$ vs. $2[1-4], p=0.06)$,
Staphylococcal infection ( $76.7 \%$ vs. $77.3 \%, p=1.00)$, Streptococcal infection (13.3\% vs. $9.1 \%, p=1.00)$ and inhospital mortality rate $(50.0 \%$ vs. $40.9 \%, p=0.52)$ between patients with NNHCA-IE and nosocomial IE.

\section{Microbiological findings}

The microbiological findings according to the site of origin are shown in Table 2. Staphylococcus aureus was the most common causative microorganism except for nonIVDU community-acquired IE. Streptococci remained the most predominant causative pathogen in this group. There were 8 culture-negative IE patients, and 3 of them had been exposed to antimicrobial therapy before the blood cultures were drawn for culture.

\section{Recognition of NNHCA-IE}

NNHCA-IE was less often clinically recognized on admission than community-acquired IE $(5 / 30,16.7 \%$ vs. $63 / 132$, $47.7 \%, p=0.002)$. NNHCA-IE were initially misdiagnosed as skin and soft tissue infection (8 episodes), catheterrelated infection (5), pneumonia (4), urinary tract infection (4), fever of undetermined focus (3) and meningitis (1). Only $43.3 \%$ of these patients received appropriate antibiotics within the first 24 hours of admission. Delay of appropriate antimicrobial therapy was significantly associated with in-hospital death in community-acquired IE patients ( $27.8 \%$ vs. $9.9 \%, p=0.007$ ), but not in NNHCA-IE patients (52.9\% vs. $46.2 \%, p=0.713$ ).

Three significantly different clinical characteristics were identified for NNHCA-IE among all IE episodes acquired outside the hospital using multivariate logistic regression analysis, as shown in Table 3. Having a Charlson comorbidity index of 2 or more was the most significant predictor (odds ratio [OR] 27.5, 95\% confidence interval [CI] 6.9-110.3, $p<0.001$ ), followed by MRSA infection and having a past history of hypertension.

\section{Risk factors for in-hospital mortality}

Twenty five percent of all the patients $(n=50)$ died during hospitalization. Patients with NNHCA-IE had the highest in-hospital mortality rate $(15 / 30,50.0 \%)$, followed by nosocomial healthcare-associated IE (9/22, 40.9\%) and community-acquired IE (26/148, 17.6\%). In-hospital mortality rate was significantly higher in NNHCA-IE compared to community-acquired IE $(p<0.001)$. Risk factors significantly associated with in-hospital death according to univariate and multivariate analysis are shown in Table 4. In multivariate logistic regression analysis, the significant risk factors for in-hospital death, after adjusting for age and sex, included shock (odds ratio $7.8,95 \%$ confidence interval 2.4-25.2, $p<0.001$ ), non-nosocomial healthcare-associated infection, alteration in consciousness, delay of appropriate antibiotics use and Staphylococci infection. 
Table 1 Comparison of clinical characteristics and outcomes of NNHCA-IE with community-acquired IE and nosocomial IE among patients admitted to the Veterans General Hospital Kaohsiung, Taiwan over a five-year period (2004 to 2009)

\begin{tabular}{|c|c|c|c|c|c|c|}
\hline & All & $\begin{array}{c}\text { Group A: } \\
\text { NNHCA-IE } \\
\mathrm{n}=30\end{array}$ & $\begin{array}{c}\text { Group B: } \\
\begin{array}{c}\text { Community-acquired IE } \\
n=148\end{array}\end{array}$ & $\begin{array}{c}\text { Group C: } \\
\text { Nosocomial IE } \\
n=22 \\
\end{array}$ & $\begin{array}{l}\text { Group } \\
\text { A vs B } \\
p \text { value }\end{array}$ & $\begin{array}{l}\text { Group } \\
\text { A vs C } \\
p \text { value }\end{array}$ \\
\hline \multicolumn{7}{|l|}{ Age, years } \\
\hline Median (range) & $50(19-92)$ & $67(45-84)$ & $44(19-88)$ & $78(43-92)$ & $<0.001$ & 0.011 \\
\hline Women, n (\%) & $48(24.0)$ & $13(43.3)$ & $28(18.9)$ & $7(31.8)$ & 0.004 & 0.399 \\
\hline Prosthetic valve, n (\%) & $18(9.0)$ & $2(6.7)$ & $15(10.1)$ & $1(4.5)$ & 0.741 & 1.000 \\
\hline \multicolumn{7}{|l|}{ Underlying diseases, n (\%) } \\
\hline $\begin{array}{l}\text { Predisposing heart } \\
\text { condition }\end{array}$ & $49(24.5)$ & $6(20.0)$ & $40(27.0)$ & $3(13.6)$ & 0.423 & 0.717 \\
\hline Diabetes mellitus & $52(26.0)$ & $17(56.7)$ & $25(16.9)$ & $10(45.5)$ & $<0.001$ & 0.424 \\
\hline Hypertension & $54(27.0)$ & $20(66.7)$ & $26(17.6)$ & $8(36.4)$ & $<0.001$ & 0.030 \\
\hline Heart failure & $35(17.5)$ & $4(13.3)$ & $25(16.9)$ & $6(27.2)$ & 0.789 & 0.290 \\
\hline HIV infected & $10(5.0)$ & $0(0)$ & $10(6.8)$ & $0(0)$ & 0.216 & NA \\
\hline IVDU & $59(29.5)$ & $0(0)$ & $59(40.0)$ & $0(0)$ & $<0.001$ & NA \\
\hline $\begin{array}{l}\text { Charlson comorbidity index, } \\
\text { median (IQR) }\end{array}$ & $1(0-2)$ & $4(2-6)$ & $0(0-1)$ & $2(1-4)$ & $<0.001$ & 0.06 \\
\hline $0-1$ & $132(66.0)$ & $3(10.0)$ & $121(81.8)$ & $8(36.4)$ & & \\
\hline $2-3$ & $34(17.0)$ & $9(30.0)$ & $19(12.8)$ & $6(27.3)$ & & \\
\hline$\geqq 4$ & $34(17.0)$ & $18(60.0)$ & $8(5.4)$ & $8(36.4)$ & & \\
\hline Dental procedure & $9(4.5)$ & $0(0)$ & $8(5.4)$ & $1(4.5)$ & 0.193 & 0.423 \\
\hline $\begin{array}{l}\text { Symptom duration, days, } \\
\text { median (IQR) }\end{array}$ & $5(3-15)$ & $4(2-7)$ & $7(3-20)$ & NA & 0.031 & NA \\
\hline \multicolumn{7}{|l|}{ Symptoms, n (\%) ${ }^{1}$} \\
\hline Constitutional & $142(71.0)$ & $26(86.7)$ & $104(70.3)$ & $12(54.5)$ & 0.065 & 0.010 \\
\hline Cardiopulmonary & $65(32.5)$ & $6(20.0)$ & $50(33.8)$ & $9(40.9)$ & 0.138 & 0.100 \\
\hline Neurological & $47(23.5)$ & $4(13.3)$ & $40(27.0)$ & $3(13.6)$ & 0.113 & 1.000 \\
\hline Gastrointestinal & $14(7.0)$ & $3(10.0)$ & $8(5.4)$ & $3(13.6)$ & 0.399 & 0.689 \\
\hline Musculoskeletal & $24(12.0)$ & $5(16.7)$ & 19 (12.8) & $0(0)$ & 0.563 & 0.065 \\
\hline \multicolumn{7}{|l|}{ Signs, $n(\%)^{2}$} \\
\hline Fever & $165(82.5)$ & $28(93.3)$ & $121(81.8)$ & $16(72.7)$ & 0.174 & 0.058 \\
\hline Heart murmur & $83(41.5)$ & $10(33.3)$ & $68(45.9)$ & $5(22.7)$ & 0.204 & 0.404 \\
\hline Skin lesions & $23(11.5)$ & $3(10.0)$ & $20(13.5)$ & $0(0)$ & 0.770 & 0.253 \\
\hline Embolism & $98(49.0)$ & $11(36.7)$ & $82(55.4)$ & $5(22.7)$ & 0.061 & 0.282 \\
\hline Altered consciousness & $34(17.0)$ & $4(13.3)$ & $28(18.9)$ & $2(9.1)$ & 0.468 & 1.000 \\
\hline Shock & $20(10.0)$ & $2(6.7)$ & $16(10.8)$ & $2(9.1)$ & 0.742 & 1.000 \\
\hline $\begin{array}{l}\text { Recognition on admission, } \\
n(\%)^{3}\end{array}$ & $68 / 162(42.0)$ & $5 / 30(16.7)$ & $63 / 132(47.7)$ & NA & 0.002 & NA \\
\hline $\begin{array}{l}\text { Appropriate antibiotics on } \\
\text { admission, } \mathrm{n}(\%)^{4}\end{array}$ & $94 / 165(57.0)$ & $13 / 30(43.3)$ & $81 / 135(60.0)$ & NA & 0.095 & NA \\
\hline \multicolumn{7}{|l|}{ Outcome } \\
\hline $\begin{array}{l}\text { Antibiotic treatment } \\
\text { duration, median days } \\
(\mathrm{IQR}, \mathrm{n})^{5}\end{array}$ & $32(28-41, n=138)$ & $28(27-40, n=17)$ & $32(28-42, n=113)$ & $34(30-40, n=8)$ & 0.258 & 0.277 \\
\hline $\begin{array}{l}\text { Hospital stay, median days } \\
(\mathrm{IQR}, \mathrm{n})^{5}\end{array}$ & $37(29-48, n=131)$ & $46(30-65, n=17)$ & $37(29-45, n=114)$ & NA & 0.181 & NA \\
\hline In-hospital death & $50(25.0)$ & $15(50.0)$ & $26(17.6)$ & $9(40.9)$ & $<0.001$ & 0.516 \\
\hline \multicolumn{7}{|c|}{${ }^{1}$ Duration from the time of onset of symptoms to admission to hospital. } \\
\hline \multicolumn{7}{|c|}{$\begin{array}{l}3 \text { The number of patients who were suspected or diagnosed to have IE within the first } 24 \text { hours of medical access. Exclude patients who were referred from } \\
\text { other hospitals with a definite diagnosis already. }\end{array}$} \\
\hline \multicolumn{7}{|c|}{${ }^{4}$ The number of patients who received antibiotics with in vitro activities against the pathogens within the first 24 hours of medical access. } \\
\hline \multicolumn{7}{|c|}{${ }^{5}$ Only patients who have received a complete course of antibiotics for IE were included. } \\
\hline
\end{tabular}


Table 2 Microorganisms causing 200 episodes of IE among patients admitted to the Veterans General Hospital Kaohsiung, Taiwan over a five-year period (2004 to 2009)

\begin{tabular}{|c|c|c|c|c|c|}
\hline \multirow[t]{2}{*}{ Pathogens } & \multirow{2}{*}{$\begin{array}{c}\text { All } \\
N=200\end{array}$} & \multicolumn{2}{|c|}{ Community-acquired IE } & \multicolumn{2}{|c|}{ Healthcare-associated IE } \\
\hline & & $\begin{array}{c}\text { non-IVDU } \\
\mathrm{n}=89\end{array}$ & $\begin{array}{l}\text { IVDU } \\
\mathrm{n}=59\end{array}$ & $\begin{array}{c}\text { non-nosocomial } \\
\mathrm{n}=30\end{array}$ & $\begin{array}{c}\text { nosocomial IE } \\
n=22\end{array}$ \\
\hline Staphylococci, n (\%) & $115(57.5)$ & $21(23.6)$ & $54(91.5)$ & $23(76.7)$ & $17(77.3)$ \\
\hline MSSA & 65 & 15 & 42 & 8 & 0 \\
\hline MRSA & 44 & 2 & 12 & 13 & 17 \\
\hline Coagulase-negative Staphylococci & 6 & 4 & 0 & 2 & 0 \\
\hline Streptococci, n (\%) & $57(28.5)$ & $50(56.2)$ & $1(1.7)$ & $4(13.3)$ & $2(9.1)$ \\
\hline Viridans streptococci & 38 & 35 & 0 & 3 & 0 \\
\hline Streptococcus bovis & 9 & 8 & 0 & 1 & 0 \\
\hline Streptococcus agalactiae & 5 & 3 & 1 & 0 & 1 \\
\hline Streptococcus pyogenes & 1 & 1 & 0 & 0 & 0 \\
\hline Streptococcus pneumoniae & 1 & 1 & 0 & 0 & 0 \\
\hline NVS & 3 & 2 & 0 & 0 & 1 \\
\hline Enterococci, n (\%) & $9(4.5)$ & $5(5.6)$ & $0(0)$ & $3(10.0)$ & $1(4.5)$ \\
\hline Enterococcus faecalis & 8 & 5 & 0 & 2 & 1 \\
\hline Enterococcus faecium & 1 & 0 & 0 & 1 & 0 \\
\hline Gram negative bacilli, n (\%) & $3(1.5)$ & $0(0)$ & $2(3.4)$ & $0(0)$ & $1(4.5)$ \\
\hline Pseudomonas aeruginosa & 1 & 0 & 1 & 0 & 0 \\
\hline Chryseobacterium indologenes & 1 & 0 & 0 & 0 & 1 \\
\hline Enterobacter cloacae & 1 & 0 & 1 & 0 & 0 \\
\hline HACEK group, n (\%) & $2(1.0)$ & $2(2.2)$ & $0(0)$ & $0(0)$ & $0(0)$ \\
\hline Haemophilus actinomycetemcomitans & 1 & 1 & 0 & 0 & 0 \\
\hline Haemophilus parainfluenzae & 1 & 1 & 0 & 0 & 0 \\
\hline Others, n (\%) & $6(3.0)$ & $5(5.6)$ & $1(1.7)$ & $0(0)$ & $0(0)$ \\
\hline Rothia dentocariosa & 2 & 1 & 1 & 0 & 0 \\
\hline Finegoldia magna & 1 & 1 & 0 & 0 & 0 \\
\hline Lactococcus lactis & 1 & 1 & 0 & 0 & 0 \\
\hline Lactococcus gravieae & 1 & 1 & 0 & 0 & 0 \\
\hline Candida albicans & 1 & 1 & 0 & 0 & 0 \\
\hline Culture negative, n (\%) & $8(4.0)$ & $6(6.7)$ & $1(1.7)$ & $0(0)$ & $1(4.5)$ \\
\hline
\end{tabular}

IE, infective endocarditis; IVDU, intravenous drug user; MSSA, methicillin-susceptible Staphylococcus aureus; MRSA, methicillin-resistant Staphylococcus aureus; NVS, nutritionally variant streptococci; HACEK, Haemophilus species, Actinobacillus actinomycetemcomitans, Cardiobacterium hominis, Eikenella corrodens, Kingella species.

Table 3 Significant differences in the clinical characteristics of patients with NNHCA-IE compared to communityacquired IE, as determined by multivariate analysis

\begin{tabular}{|c|c|c|c|c|c|c|}
\hline & \multirow{2}{*}{$\begin{array}{c}\text { NNHCA-IE } \\
n=30\end{array}$} & \multirow{2}{*}{$\begin{array}{l}\text { Community- } \\
\text { acquired IE } \\
n=148\end{array}$} & \multicolumn{2}{|c|}{ Univariate } & \multicolumn{2}{|c|}{ Multivariate ${ }^{1}$} \\
\hline & & & OR $(95 \% \mathrm{Cl})$ & $p$ value & OR $(95 \% \mathrm{Cl})$ & $p$ value \\
\hline Age $\geqq 65$ years, $n(\%)$ & $19(63.3)$ & $27(18.2)$ & $7.7(3.3-18.1)$ & $<0.001$ & & \\
\hline Women, n (\%) & $13(43.3)$ & $28(18.9)$ & $3.3(1.4-7.5)$ & 0.004 & & \\
\hline Charlson comorbidity index $\geqq 2 \mathrm{n}(\%)$ & $27(90.0)$ & $27(18.2)$ & $40.3(11.4-142.7)$ & $<0.001$ & $27.5(6.9-110.3)$ & $<0.001$ \\
\hline Diabetes mellitus, n (\%) & $17(56.7)$ & $25(16.9)$ & $6.4(2.8-14.9)$ & $<0.001$ & & \\
\hline Hypertension, n (\%) & $20(66.7)$ & $26(17.6)$ & $9.4(3.9-22.4)$ & $<0.001$ & $7.5(2.2-25.1)$ & 0.001 \\
\hline Symptoms duration $\leqq 7$ days $\mathrm{n}(\%)$ & $25(83.3)$ & $95(64.2)$ & $2.8(1.0-7.7)$ & 0.041 & & \\
\hline Staphylococci infection, n (\%) & $23(76.7)$ & $75(50.7)$ & $3.2(1.3-7.9)$ & 0.009 & & \\
\hline MRSA infection, $\mathrm{n}(\%)$ & $13(43.3)$ & $14(9.5)$ & $7.3(3.0-18.1)$ & $<0.001$ & $12.2(2.9-51.5)$ & 0.001 \\
\hline Streptococci infection, n (\%) & $4(13.3)$ & $51(34.5)$ & $0.3(0.1-0.9)$ & 0.022 & & \\
\hline
\end{tabular}

${ }^{1}$ Adjusted for age and sex.

NNHCA-IE, non-nosocomial healthcare-associated infective endocarditis; OR, odds ratio; Cl, confidence interval; MRSA, methicillin-resistant Staphylococcus aureus. 
Table 4 Predictors for in-hospital death in 200 episodes of IE among patients admitted to the Veterans General Hospital in Kaohsiung, Taiwan over a five-year period (2004 to 2009) as determined by multivariate analysis

\begin{tabular}{|c|c|c|c|c|c|c|}
\hline \multirow[t]{2}{*}{ Risk factors } & \multirow[t]{2}{*}{ All } & \multirow[t]{2}{*}{ Death } & \multicolumn{2}{|c|}{ Univariate } & \multicolumn{2}{|c|}{ Multivariate $^{1}$} \\
\hline & & & OR $(95 \% \mathrm{Cl})$ & $p$ value & OR $(95 \% \mathrm{Cl})$ & $p$ value \\
\hline Age $\geqq 65$ years & 64 & 26 & $3.2(1.6-6.2)$ & $<0.001$ & & \\
\hline Female gender & 48 & 20 & $2.9(1.4-5.8)$ & 0.002 & & \\
\hline NNHCA IE & 30 & 15 & $3.9(1.7-8.6)$ & 0.001 & $6.0(2.3-16.1)$ & $<0.001$ \\
\hline Nosocomial IE & 22 & 9 & $2.3(0.9-5.8)$ & 0.068 & & \\
\hline Prosthetic valve & 18 & 9 & $3.4(1.3-9.2)$ & 0.019 & & \\
\hline Staphylococci & 115 & 35 & $2.0(1.0-4.0)$ & 0.039 & $3.0(1.1-8.0)$ & 0.027 \\
\hline Streptococci & 57 & 6 & $0.3(0.1-0.7)$ & 0.003 & & \\
\hline \multicolumn{7}{|l|}{ Underlying conditions } \\
\hline Diabetes mellitus & 52 & 24 & $4.0(2.0-8.0)$ & $<0.001$ & & \\
\hline Hypertension & 54 & 18 & $1.8(0.9-3.5)$ & 0.098 & & \\
\hline Predisposing heart condition & 49 & 14 & $1.3(0.6-2.6)$ & 0.506 & & \\
\hline IVDU & 59 & 10 & $0.5(0.2-1.1)$ & 0.089 & & \\
\hline Charlson comorbidity index $\geqq 2$ & 68 & 30 & $4.4(2.3-8.7)$ & $<0.001$ & & \\
\hline \multicolumn{7}{|l|}{ Symptoms } \\
\hline Constitutional & 142 & 34 & $0.8(0.4-1.7)$ & 0.589 & & \\
\hline Cardiopulmonary & 65 & 18 & $1.2(0.6-2.4)$ & 0.542 & & \\
\hline Neurological & 47 & 15 & $1.6(0.8-3.2)$ & 0.211 & & \\
\hline Gastrointestinal & 14 & 4 & $1.2(0.4-4.1)$ & 0.749 & & \\
\hline Musculoskeletal & 24 & 5 & $0.8(0.3-2.2)$ & 0.615 & & \\
\hline \multicolumn{7}{|l|}{ Signs } \\
\hline Fever & 165 & 41 & $1.0(0.4-2.2)$ & 0.914 & & \\
\hline Heart murmur & 83 & 19 & $0.8(0.4-1.6)$ & 0.562 & & \\
\hline Alteration in consciousness & 34 & 15 & $3.0(1.4-6.4)$ & 0.005 & $3.9(1.4-11.1)$ & 0.012 \\
\hline Shock & 20 & 13 & $7.2(2.7-19.3)$ & $<0.001$ & $7.8(2.4-25.2)$ & 0.001 \\
\hline Unrecognition on admission ${ }^{2}$ & $94 / 162$ & 25 & $1.3(0.6-2.7)$ & 0.509 & & \\
\hline Delay of appropriate antibiotics ${ }^{3}$ & $71 / 165$ & 24 & $2.9(1.4-6.2)$ & 0.004 & $3.7(1.5-9.1)$ & 0.004 \\
\hline
\end{tabular}

${ }^{1}$ Adjusted for age and sex.

2 Patients who were not suspected or diagnosed to have IE within the first 24 hours of medical access.

${ }^{3}$ Patients didn't receive antibiotics with in vitro activities against the pathogens within the first 24 hours of medical access.

IE, infective endocarditis; OR, odds ratio; Cl, confidence interval; NNHCA, non-nosocomial healthcare-associated; IVDU, intravenous drug user

\section{Discussion}

Non-nosocomial healthcare-associated infective endocarditis (NNHCA-IE) is a new category of IE that often goes unrecognized in Taiwan. This is the first study to describe the clinical characteristics and outcomes of NNHCA-IE in Eastern Asia and emphasize the differences between NNHCA-IE and community-acquired IE. This study also describes the changing distribution of the causative microorganisms of IE in Taiwan. Five independent predictors for in-hospital death were identified.

In our study clinical features and outcomes of patients with NNHCA-IE were very different from those with community-acquired IE, but similar to those with nosocomial IE. The findings were comparable to those in a previous study[14]. However, it is easy to mistake NNHCA-IE for community-acquired IE, since both appear to be acquired outside the hospital. Symptoms and signs of IE patients at presentation were not helpful in distinguishing between these two categories of IE. We identified 3 independent predictors for all IE episodes acquired out of the hospital to be non-nosocomial healthcare-associated, including having a Charlson comorbidity index of 2 or more, having a history of hypertension and MRSA infection. Clinicians should be alert to the possibility of NNHCA-IE when patients with IE present with these 3 different clinical features.

Early recognition of IE enables clinicians to initiate appropriate antimicrobial therapy early. However, only $15.4 \%$ of NNHCA-IE patients were suspected or diagnosed to have IE on admission. The percentage was significantly lower than that of community-acquired IE patients. There are two possible explanations. First, patients with NNHCA-IE were less likely to present with embolic phenomena or a heart murmur than those with communityacquired IE. Second, many clinicians are not familiar with the atypical presentations of the new category of IE.

Only $43.3 \%$ of patients with NNHCA-IE received appropriate antimicrobial therapy on the first day. Delay 
of appropriate antimicrobial therapy was an independent predictor for in-hospital death in all IE patients, but not in NNHCA-IE patients. We propose two possible explanations. First, patients with NNHCA-IE had more underlying diseases, which were mainly responsible for the poor outcome and masked the impact of inappropriate antimicrobial therapy. Second, the case number of NNHCA-IE in our series was small. Further larger, prospective studies may be needed to evaluate the impact of inappropriate antimicrobial therapy on NNHCA-IE.

NNHCA-IE is an emerging category of IE. In a population-based study of IE, 50\% of IE patients between 2001 and 2006 were non-nosocomial healthcare-associated. The percentage was higher than that of communityacquired IE (42.5\%) and nosocomial IE (7.5\%) [31]. In our study, NNHCA-IE accounted for $15 \%$ of all IE episodes. This is similar to the rates in the ICE-PCS study $(254 / 1622,15.7 \%)$ [14]. The rates of NNHCA-IE in Taiwan were lower than those in North America, but higher than South America and Europe [15]. Non-nosocomial acquisition accounted for $58 \%$ of health care-associated IE episodes at our medical center. This is slightly higher than the $46 \%$ reported in ICE-PCS [14]. Taiwan is a country in which $99.5 \%$ of the population is covered by national health insurance. This has augmented access to medical clinics, regional hospitals, hemodialysis and chronic care centers. Improved access to medical care, accompanied by advances in invasive medical procedures, increased the proportion of outpatient procedures and care, which further contributed to the frequency of NNHCA-IE.

There are only limited reports of the microbiological epidemiology of IE in Eastern Asian countries during the past decade $[4,5,19-21,23]$. Some report Staphylococci [19-21], others found Streptococci $[4,5,23]$ to be most common pathogens. None of these studies included the underlying risk factors for the new classification of IE. We found Staphylococcus aureus to be the most frequent causative pathogen, except for non-IVDU community-acquired IE, where viridans Streptococci remain the predominant pathogen. Our findings are in accordance with those in the ICE-PCS [14]. The major difference was that our study population had a relatively low proportion of Enterococci (4.5\%) compared to $8.0 \%-19.5 \%$ in western countries $[1,2,7,8,11,15,32,33]$.

We identified 5 risk factors for in-hospital death by multivariate logistic regression analysis. Most are known independent predictors of mortality. These included shock [2,5], non-nosocomial healthcare-associated infection, alteration in consciousness [4,5], delay of appropriate antibiotics use [34,35] and Staphylococci infection $[5,14]$. Healthcare-associated infection has been identified to be associated with poor outcome in IE [14]. In our study, patients with non-nosocomial acquisition had an even higher risk for in-hospital death. Patients with NNHCA-IE also had many comorbid conditions requiring frequent medical care and exposure. Increased awareness of clinicians to this disease entity could reduce mortality associated with NNHCA-IE.

This current study has several limitations. First, the retrospective design of the current study may have missed some clinical features such as new heart murmurs or ascertainment of healthcare-associated criteria in some of the community-acquired IE cases. Second, we were unable to determine long-term survival and emergence of further complications following discharge from the hospital. Third, it was conducted in a single teaching hospital. Nevertheless, the age and sex of patients were comparable to those in previous studies $[4,5,19]$, including the large Taiwan nationwide population-based IE study that included 7240 patients [5].

\section{Conclusions}

In conclusion, NNHCA-IE accounted for $15 \%$ of IE in Taiwan, but was frequently unrecognized. It was associated with a higher in-hospital mortality rate than community-acquired IE. Increased awareness of this new category of IE is crucial to optimize therapy and improve the outcome associated with this entity.

\section{Acknowledgements and Funding}

The authors wish to express their appreciation to Dr. Calvin M. Kunin for his helpful suggestions and critical review of the manuscript. The study was conducted without any financial support.

\section{Author details}

${ }^{1}$ Divison of Infectious Diseases, Department of Medicine, Kaohsiung Veterans General Hospital, 386 Ta-Chung 1st Road, Kaohsiung 813, Taiwan. ${ }^{2}$ School of Medicine, National Yang-Ming University, No.155, Section 2, Linong Street, Taipei 112 Taiwan. ${ }^{3}$ Graduate Institute of Environmental Education, National Kaohsiung Normal University, No.116, Heping 1st Road, Kaohsiung 802, Taiwan.

\section{Authors' contributions}

KSW participated in the design of the study, performed data analysis and drafted the manuscript. SSJL participated in the design of the study, assisted in data interpretation and gave crucial revision to this manuscript. HCT participated in the design of the study and gave crucial revision to this manuscript. SRW gave critical suggestions to the designs of the study and the manuscript. JKC, CLS, YHW and YTT participated in data collection, interpretation and analysis. YSC supervised the research group and gave final approval of the version to be submitted. All authors read and approved the final manuscript.

\section{Competing interests}

The authors declare that they have no competing interests.

Received: 29 March 2011 Accepted: 17 August 2011

Published: 17 August 2011

\section{References}

1. Hoen B, Alla F, Selton-Suty C, Beguinot I, Bouvet A, Briancon S, Casalta JP, Danchin N, Delahaye F, Etienne J, et al: Changing profile of infective endocarditis: results of a 1-year survey in France. JAMA 2002, 288:75-81.

2. Ferreiros E, Nacinovich F, Casabe JH, Modenesi JC, Swieszkowski S, Cortes C, Hernan CA, Kazelian L, Varini S: Epidemiologic, clinical, and microbiologic 
profile of infective endocarditis in Argentina: a national survey. The Endocarditis Infecciosa en la Republica Argentina-2 (EIRA-2) Study. Am Heart J 2006, 151:545-552.

3. Mylonakis E, Calderwood SB: Infective endocarditis in adults. N Engl I Med 2001, 345:1318-1330

4. Hsu CN, Wang JY, Tseng CD, Hwang JJ, Hsueh PR, Liau CS: Clinical features and predictors for mortality in patients with infective endocarditis at a university hospital in Taiwan from 1995 to 2003. Epidemiol Infect 2006, 134:589-597.

5. Lee CH, Tsai WC, Liu PY, Tsai LM, Ho MT, Chen JH, Lin L: Epidemiologic features of infective endocarditis in Taiwanese adults involving native valves. Am J Cardiol 2007, 100:1282-1285.

6. Loupa C, Mavroidi N, Boutsikakis I, Paniara O, Deligarou O, Manoli H, Saroglou G: Infective endocarditis in Greece: a changing profile. Epidemiological, microbiological and therapeutic data. Clin Microbiol Infect 2004, 10:556-561.

7. Cabell CH, Jollis JG, Peterson GE, Corey GR, Anderson DJ, Sexton DJ, Woods CW, Reller LB, Ryan T, Fowler VG Jr: Changing patient characteristics and the effect on mortality in endocarditis. Arch Intern Med 2002, 162:90-94.

8. Hill EE, Herijgers P, Claus P, Vanderschueren S, Herregods MC, Peetermans WE: Infective endocarditis: changing epidemiology and predictors of 6-month mortality: a prospective cohort study. Eur Heart $\rfloor$ 2007, 28:196-203.

9. Mathew J, Addai T, Anand A, Morrobel A, Maheshwari P, Freels S: Clinical features, site of involvement, bacteriologic findings, and outcome of infective endocarditis in intravenous drug users. Arch Intern Med 1995 155:1641-1648.

10. Moreillon P, Que YA: Infective endocarditis. Lancet 2004, 363:139-149.

11. Bouza E, Menasalvas A, Munoz P, Vasallo FJ, del Mar Moreno M, Garcia Fernandez MA: Infective endocarditis-a prospective study at the end of the twentieth century: new predisposing conditions, new etiologic agents, and still a high mortality. Medicine (Baltimore) 2001, 80:298-307.

12. Martin-Davila P, Fortun J, Navas E, Cobo J, Jimenez-Mena M, Moya JL, Moreno S: Nosocomial endocarditis in a tertiary hospital: an increasing trend in native valve cases. Chest 2005, 128:772-779.

13. Garner JS, Jarvis WR, Emori TG, Horan TC, Hughes JM: CDC definitions for nosocomial infections, 1988. Am J Infect Control 1988, 16:128-140.

14. Benito N, Miro JM, de Lazzari E, Cabell CH, del Rio A, Altclas J, Commerford P, Delahaye F, Dragulescu S, Giamarellou H, et al: Health careassociated native valve endocarditis: importance of non-nosocomial acquisition. Ann Intern Med 2009, 150:586-594.

15. Murdoch DR, Corey GR, Hoen B, Miro JM, Fowler VG Jr, Bayer AS, Karchmer AW, Olaison L, Pappas PA, Moreillon P, et al: Clinical presentation, etiology, and outcome of infective endocarditis in the 21st century: the International Collaboration on Endocarditis-Prospective Cohort Study. Arch Intern Med 2009, 169:463-473.

16. Fowler VG Jr, Miro JM, Hoen B, Cabell CH, Abrutyn E, Rubinstein E, Corey GR, Spelman D, Bradley SF, Barsic B, et al: Staphylococcus aureus endocarditis: a consequence of medical progress. JAMA 2005, 293:3012-3021.

17. Habib G, Hoen B, Tornos P, Thuny F, Prendergast B, Vilacosta I, Moreillon P, de Jesus Antunes M, Thilen U, Lekakis J, et al: Guidelines on the prevention, diagnosis, and treatment of infective endocarditis (new version 2009): the Task Force on the Prevention, Diagnosis, and Treatment of Infective Endocarditis of the European Society of Cardiology (ESC). Endorsed by the European Society of Clinical Microbiology and Infectious Diseases (ESCMID) and the International Society of Chemotherapy (ISC) for Infection and Cancer. Eur Heart J 2009, 30:2369-2413

18. Wang JL, Hung CC, Hsieh SM, Chang SC: Clinical features and outcome analysis of infective endocarditis in elderly patients. J Formos Med Assoc 2004, 103:416-421.

19. Yiu KH, Siu CW, Lee KL, Fong YT, Chan HW, Lee SW, Lau CP, Tse HF: Emerging trends of community acquired infective endocarditis. Int J Cardiol 2007, 121:119-122.

20. Huang TY, Tseng HK, Liu CP, Lee CM: Comparison of the clinical manifestations of infective endocarditis between elderly and young patients - a 3-year study. J Microbiol Immunol Infect 2009, 42:154-159.
21. Chao TH, Li YH, Tsai WC, Tsai LM, Lin LJ, Chen JH, Yang YJ: Prognostic determinants of infective endocarditis in the 1990s. J Formos Med Assoc 1999, 98:474-479.

22. Chao TH, Li YH, Tsai WC, Lin LJ, Chen JH, Tsai LM, Luo CY, Yang YJ, Liu PY: Clinical characteristics and prognostic determinants of infective endocarditis in adult intravenous drug users. J Formos Med Assoc 2004, 103:754-760

23. Lou XF, Yang DY, Liu ZY, Wang HL, Li TS: [Clinical analysis of 120 cases of infective endocarditis]. Zhonghua Nei Ke Za Zhi 2009, 48:35-38.

24. Li JS, Sexton DJ, Mick N, Nettles R, Fowler VG Jr, Ryan T, Bashore T, Corey GR: Proposed modifications to the Duke criteria for the diagnosis of infective endocarditis. Clin Infect Dis 2000, 30:633-638.

25. Charlson ME, Pompei P, Ales KL, Mackenzie CR: A new method of classifying prognostic comorbidity in longitudinal studies: development and validation. J Chronic Dis 1987, 40:373-383.

26. Friedman ND, Kaye KS, Stout JE, McGarry SA, Trivette SL, Briggs JP, Lamm W, Clark C, MacFarquhar J, Walton AL, et al: Health care-associated bloodstream infections in adults: a reason to change the accepted definition of community-acquired infections. Ann Intern Med 2002, 137:791-797.

27. Gilleece A, Fenelon L: Nosocomial infective endocarditis. J Hosp Infect 2000, 46:83-88.

28. Dajani AS, Bisno AL, Chung KJ, Durack DT, Freed M, Gerber MA, Karchmer AW, Millard HD, Rahimtoola S, Shulman ST, et al: Prevention of bacterial endocarditis. Recommendations by the American Heart Association. Jama 1990, 264:2919-2922.

29. Durack DT, Lukes AS, Bright DK: New criteria for diagnosis of infective endocarditis: utilization of specific echocardiographic findings. Duke Endocarditis Service. Am J Med 1994, 96:200-209.

30. Ioannidou E, Falagas ME: The difference between adequate and appropriate antimicrobial treatment. Clin Infect Dis 2008, 46:642-644.

31. de Sa DD, Tleyjeh IM, Anavekar NS, Schultz JC, Thomas JM, Lahr BD, Bachuwar A, Pazdernik M, Steckelberg JM, Wilson WR, Baddour LM: Epidemiological trends of infective endocarditis: a population-based study in Olmsted County, Minnesota. Mayo Clin Proc 2010, 85:422-426.

32. Fernandez-Hidalgo $N$, Almirante $B$, Tornos $P$, Pigrau C, Sambola A, Igual A, Pahissa A: Contemporary epidemiology and prognosis of health careassociated infective endocarditis. Clin Infect Dis 2008, 47:1287-1297.

33. Giannitsioti E, Skiadas I, Antoniadou A, Tsiodras S, Kanavos K, Triantafyllidi H, Giamarellou H: Nosocomial vs. community-acquired infective endocarditis in Greece: changing epidemiological profile and mortality risk. Clin Microbiol Infect 2007, 13:763-769.

34. Hricak V, Matejicka F, Sedlak T, Duris I, Milovsky V, Kovacik J, Marks P, West D, Krcmery V Jr: Native valve staphylococcal endocarditis: etiology, risk factors and outcome in 53 cases. J Chemother 1998, 10:360-368.

35. Kollef MH, Sherman G, Ward S, Fraser VJ: Inadequate antimicrobial treatment of infections: a risk factor for hospital mortality among critically ill patients. Chest 1999, 115:462-474.

\section{Pre-publication history}

The pre-publication history for this paper can be accessed here: http://www.biomedcentral.com/1471-2334/11/221/prepub

doi:10.1186/1471-2334-11-221

Cite this article as: Wu et al:: Non-nosocomial healthcare-associated infective endocarditis in Taiwan: an underrecognized disease with poor outcome. BMC Infectious Diseases 2011 11:221. 